\title{
Structure and function of echinoderm telomerase RNA
}

\author{
JOSHUA D. PODLEVSKY, ${ }^{1}$ YANG LI, ${ }^{1,2}$ and JULIAN J.-L. CHEN \\ School of Molecular Sciences, Arizona State University, Tempe, Arizona 85287, USA
}

\begin{abstract}
Telomerase is a ribonucleoprotein (RNP) enzyme that requires an integral telomerase RNA (TR) subunit, in addition to the catalytic telomerase reverse transcriptase (TERT), for enzymatic function. The secondary structures of TRs from the three major groups of species, ciliates, fungi, and vertebrates, have been studied extensively and demonstrate dramatic diversity. Herein, we report the first comprehensive secondary structure of TR from echinoderms-marine invertebrates closely related to vertebratesdetermined by phylogenetic comparative analysis of 16 TR sequences from three separate echinoderm classes. Similar to vertebrate TR, echinoderm TR contains the highly conserved template/pseudoknot and H/ACA domains. However, echinoderm TR lacks the ancestral CR4/5 structural domain found throughout vertebrate and fungal TRs. Instead, echinoderm TR contains a distinct simple helical region, termed eCR4/5, that is functionally equivalent to the CR4/5 domain. The urchin and brittle star eCR4/5 domains bind specifically to their respective TERT proteins and stimulate telomerase activity. Distinct from vertebrate telomerase, the echinoderm TR template/pseudoknot domain with the TERT protein is sufficient to reconstitute significant telomerase activity. This gain-of-function of the echinoderm template/pseudoknot domain for conferring telomerase activity presumably facilitated the rapid structural evolution of the eCR4/5 domain throughout the echinoderm lineage. Additionally, echinoderm TR utilizes the template-adjacent P1.1 helix as a physical template boundary element to prevent nontelomeric DNA synthesis, a mechanism used by ciliate and fungal TRs. Thus, the chimeric and eccentric structural features of echinoderm TR provide unparalleled insights into the rapid evolution of telomerase RNP structure and function.
\end{abstract}

Keywords: telomere; RNA structure; ribonucleoprotein; template boundary; evolution

\section{INTRODUCTION}

The telomerase ribonucleoprotein (RNP) enzyme synthesizes short DNA repeats onto linear eukaryotic chromosome termini to offset the progressive loss of telomeric DNA during replication, ensuring genome stability and cellular replicative capacity (Zakian 2009). The minimal telomerase enzyme necessary and sufficient for the reconstitution of telomerase activity is composed of the catalytic telomerase reverse transcriptase (TERT) and the telomerase RNA (TR) component that harbors a short template region for telomeric DNA synthesis (Podlevsky and Chen 2012). TRs from evolutionarily distinct groups of eukaryotic species are profoundly divergent, differing immensely in nucleotide sequence, length, and overall secondary structure (Chen and Greider 2004; Podlevsky et al. 2008).

Despite the massive difference in gross architecture, all known TRs contain two universal and indispensable structural domains: the template proximal pseudoknot and a stimulatory distal stem-loop moiety (Chen et al. 2002;

\footnotetext{
${ }^{1}$ These authors contributed equally to this work.

${ }^{2}$ Present address: Barrow Neurological Institute, Phoenix, AZ 85013, USA

Corresponding author: jlchen@asu.edu

Article published online ahead of print. Article and publication date are at http://www.rnajournal.org/cgi/doi/10.1261/rna.053280.115.
}

Schmidt and Cech 2015). Within vertebrate TRs, this distal stem-loop moiety is termed CR4/5 (conserved regions 4 and 5) and composed of a three-way junction of the P5, P6, and P6.1 stem-loops. A remarkably similar structure with an identical function has been recently identified and found to be absolutely conserved across the evolutionary distant filamentous fungal and fission yeast TRs (Qi et al. 2013). In addition to the template/pseudoknot and CR4/5 domains, there are immense species-specific structural differences within TR that appear in concert with the plethora of species-specific TR binding proteins. This includes RNA helicase RHAU, TCAB1, and box H/ACA dyskerin protein complex in vertebrates; Est1, Est3, Ku70/80 heterodimer, and Sm ring complex in fungi; p50 and p65 in ciliates; and box C/D Nop58 and MTAP (TCAB1 homolog) in flagellates (Mitchell et al. 1999; Seto et al. 1999; Hughes et al. 2000; Venteicher et al. 2009; Lattmann et al. 2011; Sexton and Collins 2011; Egan and Collins 2012; Singh et al. 2012; Tang et al. 2012; Gupta et al. 2013). These unique sets of TR accessory

\footnotetext{
(c) 2016 Podlevsky et al. This article is distributed exclusively by the RNA Society for the first 12 months after the full-issue publication date (see http://rnajournal.cshlp.org/site/misc/terms.xhtml). After 12 months, it is available under a Creative Commons License (Attribution-NonCommercial 4.0 International), as described at http://creativecommons.org/licenses/ by-nc/4.0/.
} 
proteins are essential for TR localization, maturation, and RNP assembly (Schmidt and Cech 2015).

Due to the close proximity of echinoderms to vertebrates, the echinoderm TR identified from the purple sea urchin (Strongylocentrotus purpuratus) has the expected conservation of the template proximal pseudoknot and the $3^{\prime}$ H/ACA domains, homologous to those in vertebrate $\mathrm{TR}$ ( $\mathrm{Li}$ et al. 2013). However, it was surprising that the central domain of purple sea urchin TR would lack the ancestral vertebrate CR4/5 structural domain. Thus, additional sequences and biochemical analysis of echinoderm TR are necessary to determine the extent of conservation for these apparent echinoderm-specific structural elements as well as their functional relevance for telomerase RNP assembly and enzymatic activity.

To determine echinoderm TR secondary structure by phylogenetic sequence analysis, it is necessary to obtain TR sequences from each major clade of echinoderm species. However, this task is complicated by the high variation of TR sequences from even closely related groups of species, which prevents degenerate PCR-based strategies (Chen et al. 2000; Podlevsky and Chen 2012). A variety of biochemical enrichment protocols and computational screening methodologies have been developed to improve the rate of TR identification from previously unexplored groups of species (Greider and Blackburn 1989; Leonardi et al. 2008; Webb and Zakian 2008; Xie et al. 2008; Gunisova et al. 2009; Cifuentes-Rojas et al. 2011; Li et al. 2013; Qi et al. 2013). Unfortunately, the vast majority of these methodologies are incompatible with TR identification from echinoderm species; as they typically rely on either established genetic tools, small genome size, abundant telomerase enzyme, or a longer template length. Furthermore, with the exception of the purple sea urchin, no echinoderm species has a complete genome sequenced, assembled, annotated and publicly available (Sodergren et al. 2006; Cameron et al. 2015). The scarcity of completed and annotated echinoderm genomes precludes the approach of targeting syntenic protein genes flanking the TR gene, which has been successfully used for several sensu stricto Saccharomyces species (Dandjinou et al. 2004) and plants (Beilstein et al. 2012). Thus, ancillary avenues for the identification of additional echinoderm TRs are necessary to elucidate the exceedingly divergent TR structures from this group of species.

Herein we report the secondary structure of echinoderm TR determined by phylogenetic comparative and biochemical analyses. Similar to the purple sea urchin TR, additional echinoderm TRs identified in this study contain a conserved template/pseudoknot domain with a template-adjacent helix for template boundary definition and an H/ACA domain for biogenesis. The structure of the purple sea urchin TR central domain is moderately conserved in other sea urchin and sand dollar species, while brittle and feather star TRs have a distinct structure in their central domain. Functional analysis revealed that the echinoderm template/pseudoknot domain alone is sufficient to reconstitute significant telomerase activity with the TERT protein, while a short helical region from the central domain moderately stimulates activity. The chimeric structural features of echinoderm TR demonstrates the innate molecular flexibility of the telomerase RNP for maintaining sufficient function yet permitting rapid divergence in sequence and structure of integral TR domains.

\section{RESULTS}

The identification of the first invertebrate TR from the purple sea urchin provided an initial glimpse of conservation and the peculiar loss of critical vertebrate TR structural features within echinoderms ( $\mathrm{Li}$ et al. 2013). Despite the close evolutionary relationship between vertebrates and echinoderms, the essential CR $4 / 5$ structural domain of vertebrate TR is seemingly absent from purple sea urchin TR. This was unexpected since the CR4/5 domain is absolutely conserved in the evolutionarily distant vertebrate, filamentous fungal and fission yeast TRs (Qi et al. 2013). To elucidate the extent to which ancestral structural features of TR have diversified and become unrecognizable within echinoderms, while retaining telomerase function, we identified 14 new invertebrate TRs from a broad range of echinoderm species using three distinct strategies and performed phylogenetic comparative analysis to infer the conserved secondary structure of echinoderm TR.

The strategies used in this study for TR identification are different from our previous approach for identification of purple sea urchin TR (Li et al. 2013). In our previous study, the biochemical enrichment of purple sea urchin TR relied on immunoprecipitation using antibodies targeting the 5'-TMG cap. While a 5'-TMG cap has been experimentally confirmed for vertebrate, yeast, and the purple sea urchin TRs, very little is known for other echinoderm TRs (Seto et al. 1999; Jády et al. 2004; Li et al. 2013). The additional TR biochemical enrichment step depended on coimmunoprecipitation with the corresponding recombinant-tagged TERT protein. This step is challenging due to the lack of additional echinoderm TERT proteins identified (Podlevsky et al. 2008). Moreover, the lack of completed echinoderm genomes impedes echinoderm TERT protein identification and precludes syntenic gene searches (Sodergren et al. 2006; Cameron et al. 2015). To overcome these challenges, we therefore developed a separate TR biochemical enrichment strategy for identifying TR from additional echinoderm species, avoiding the anti-TMG and TERT-binding coimmunoprecipitation steps.

Our initial strategy for echinoderm TR identification from species closely related to purple sea urchin was degenerate PCR with primers targeting sequences within the template/ pseudoknot and H/ACA domains (Chen et al. 2000; Li et al. 2013). The targeted sequences are well conserved between purple sea urchin and vertebrate TRs. With this approach, we successfully identified three new echinoderm 


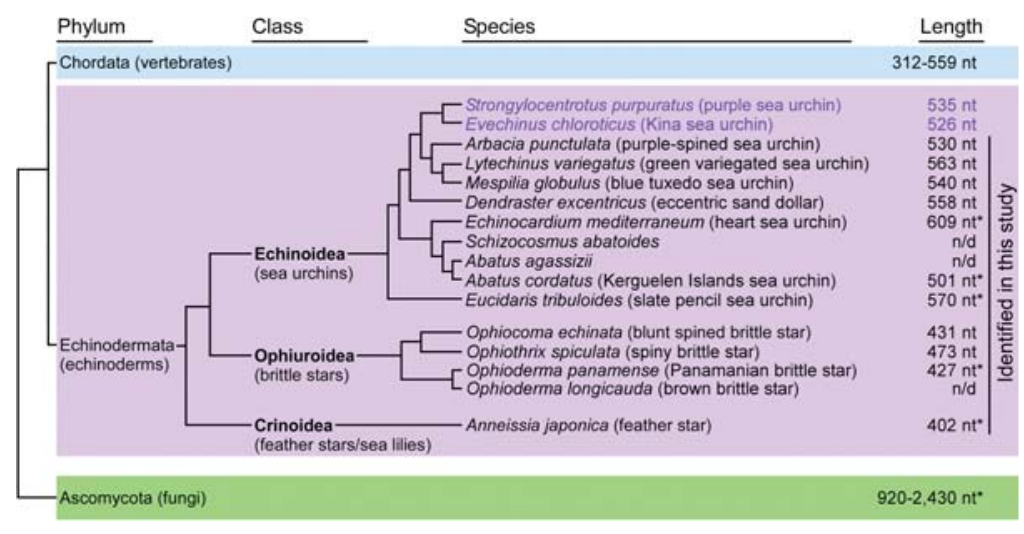

FIGURE 1. Identification of echinoderm TRs. Eight sea urchins, a sand dollar (Dendraster excentricus), three brittle star, and a feather star (Anneissia japonica) TR species were identified in this study (black text) with two sea urchin TRs (violet text) previously identified (Li et al. 2013; Gillard et al. 2014). The TR length was determined by $5^{\prime}$ - and $3^{\prime}$-RACE, estimated from the position of the box ACA in the sequencing data $(*)$, or not determined (n/d). Echinoderms comprise the sister classes Echinoidea (sea urchins and sand dollars), Ophiuroidea (brittle stars), and the ancestral Crinoidea class (sea lilies and feather stars). The vertebrate lineage (phylum Chordata, blue) is closely related to the echinoderm lineage (light violet), while fungi (phylum Ascomycota, green) are the out-group.

TR sequences from two distinct orders of sea urchins: the purple-spined sea urchin (Arbacia punctulata) from the order Arbacoida as well as the green variegated (Lytechinus variegatus), and blue tuxedo (Mespilia globulus) sea urchins from the order Temnopleuroida (Fig. 1). Sequence alignment of the identified sea urchin TRs revealed a highly conserved sequence in the template/pseudoknot domain, similar to that of vertebrate TRs (Supplemental Fig. S1). However, further attempts to identify TRs from the more distantly related echinoderm orders using a degenerate PCR strategy were unsuccessful and necessitated an alternative approach.

To identify TRs from more distantly related echinoderm orders, we used a next-generation sequencing-based approach adapted from our previously reported strategy (Li et al. 2013). We chose two target species outside of the sea urchin family: the eccentric sand dollar (Dendraster excentricus) and Panamanian serpent brittle star (Ophioderma panamense) (Fig. 1). Sand dollars are closely related to sea urchins, belonging to the same echinoderm class Euechinoidea, yet from a separate order Clypeasteroida (Perseke et al. 2010). Brittle stars are more distantly related, belonging to the separate class Ophiuroidea. Total RNA was isolated from gonadal tissues and enriched for TR by a size-selection step to deplete ribosomal RNAs, mRNAs and small RNAs prior to RNA-seq analysis. RNA species ranging in size from 300 to $700 \mathrm{nt}$ were purified by polyacrylamide gel electrophoresis (PAGE). This size range was chosen based on the length of the four sea urchin TRs (530-563 nt) and all known vertebrate TRs (312-559 nt) (Podlevsky et al. 2008). A caveat of this purification step was that the TR of interest must have a length within this range. The size-selected RNA was then used for cDNA library construction (see Materials and Methods). Next-generation sequencing of the two cDNA li- braries generated over 75 million and 77 million 50-bp sequencing reads for sand dollar and brittle star, respectively. The RNA-seq data from these two species were independently de novo assembled into contigs using the Trinity assembly program (Haas et al. 2013). The assembled contigs were searched for putative TR sequences using the Fragrep2 program (Mosig et al. 2006) and positionspecific weight matrices (PWM) derived from the sequence alignment of the four sea urchin TRs (Supplemental Fig. S1B). The Fragrep2 search produced a single hit from each of the sand dollar and brittle star data sets. Mapping the respective TR $5^{\prime}$ - and $3^{\prime}$-ends by RACE revealed that the eccentric sand dollar and brittle star TRs are 558 and $427 \mathrm{nt}$ in length, respectively, within the range of our PAGE size selection (Fig. 1). Each TR demonstrated sequence conservation in the template/pseudoknot and H/ACA domains, however, the brittle star TR central domain could not be aligned with urchin TR sequences (Supplemental Figs. S2, S3).

For our last echinoderm TR search strategy, we then performed computational analysis of publicly available transcriptome data. The echinoderm transcriptome data obtained from the National Center for Biotechnology Information Sequencing Read Archive (http://www.ncbi. nlm.nih.gov/sra) were de novo assembled into contigs and searched with the Fregrep2 program using a new PWM pattern improved by including the sand dollar and brittle star TR sequences. Through this computational approach, we identified nine TR sequences from three separate echinoderm classes: five sea urchins from Echinoidia, two brittle stars from Ophiuroidea, and a feather star from the basal class Crinoidea (Fig. 1).

\section{Echinoderm TR utilizes a distinct mechanism for template boundary definition}

The secondary structures of echinoderm TRs from purple sea urchin, blunt spined brittle star, and feather star-each representing a distinct echinoderm class-were discerned by phylogenetic comparative analysis (Fig. 1). Phylogenetic comparative analysis identifies nucleotides that vary in concert among species while maintaining Watson-Crick basepairing, inferring helical regions in the secondary structure (Chen et al. 2000). Due to the low level of sequence conservation between echinoderm classes, TR primary sequences from each class of species were aligned separately (Supplemental Figs. S2-S4). The secondary structures for the three echinoderm TRs were constructed based on nucleotide covariations from these multiple sequence alignments. 
Despite the limited number of universally conserved residues, the template/pseudoknot domain of echinoderm and vertebrate TRs share homologous architectures (Fig. 2A-D). Interestingly, the echinoderm TR template/pseudoknot domain harbors a short template-adjacent helix, termed P1.1, downstream from the pseudoknot core enclosing P1 stem. While a template-adjacent stem-loop is commonly present in fungal and specific ciliate TRs, it is absent in all known vertebrate
A

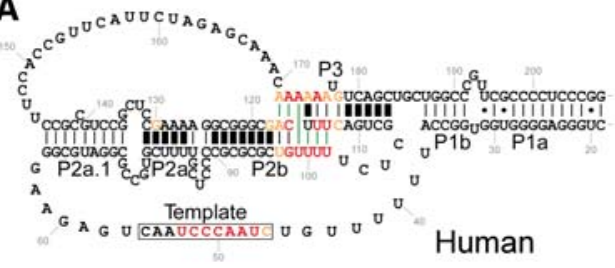

C

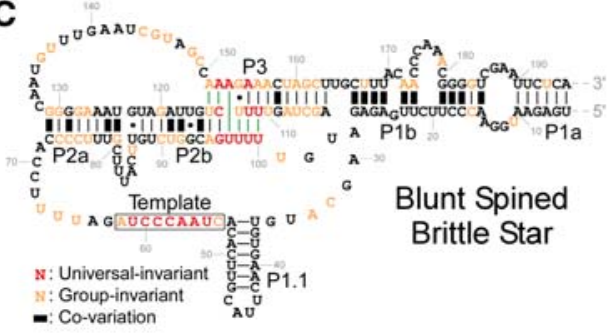

B

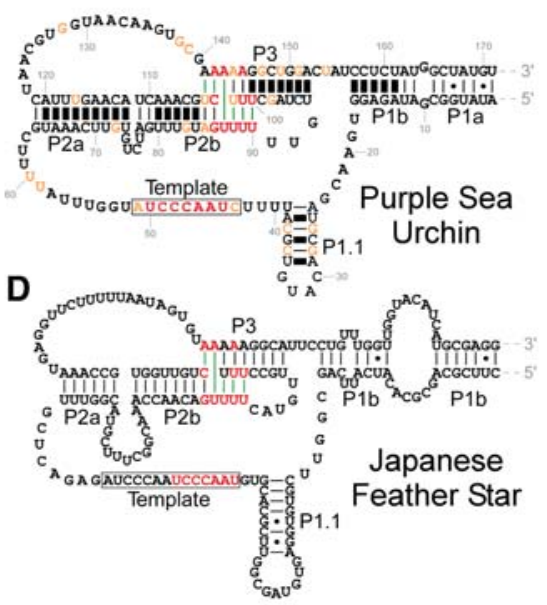

E

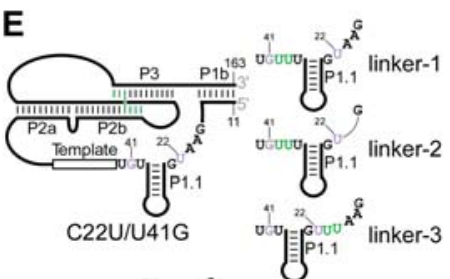

$\mathbf{F}$

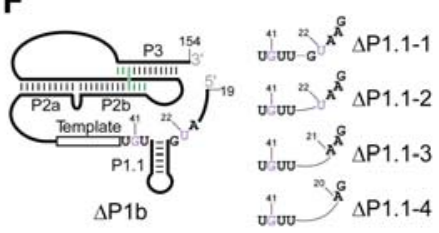

G

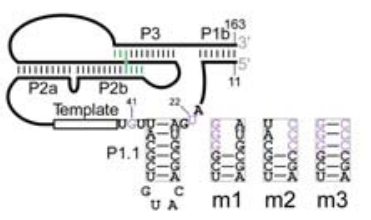

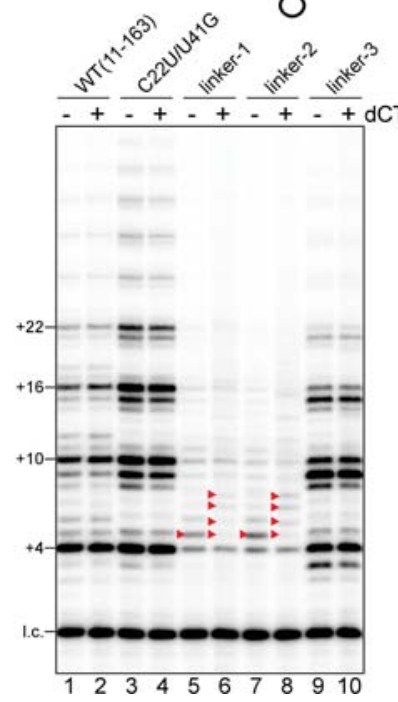
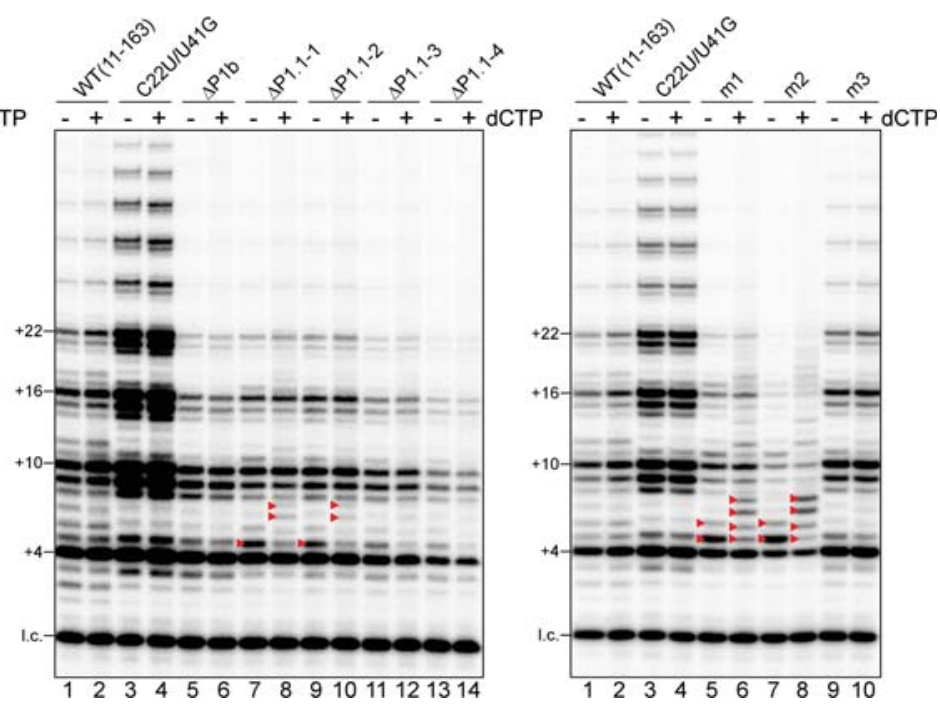

FIGURE 2. Echinoderm TR template/pseudoknot domain contains a template-adjacent helix for template boundary definition. Comparison of representative TR template/pseudoknot domains from vertebrate, human $(A)$; sea urchin, purple sea urchin $(B)$; brittle star, blunt spined brittle star $(C)$; and feather star, Japanese feather star $(D)$. The hallmark triple helix within the TR pseudoknot (green) is denoted within each structure. Covariation (black bar), universal-invariant between vertebrates and echinoderm (red), and group-invariant (orange) nucleotides for vertebrate, sea urchin, and brittle star TR template/pseudoknot domains are based on multiple sequence alignment of 42 vertebrate (Chen et al. 2000; Podlevsky et al. 2008; Xie et al. 2008), nine sea urchin/sand dollar, three brittle star, and a feather star species (see Supplemental Fig. S2). (E-G, top) Schematic of the purple sea urchin TR template/pseudoknot domain denoting nucleotide mutations (violet), insertions (green), and truncations to determine P1.1 functionality for template definition. (E-G, bottom) Functional analysis of purple sea urchin TR mutations and truncation variants by the direct primer-extension assay. Sea urchin TR template/pseudoknot variants (fragment 11-163 nt) and the central domain fragment (186-456 nt) were assembled in vitro with the sea urchin TERT protein. Sea urchin telomerase variants were assayed with the 18 -mer DNA primer (TTAGGG) ${ }_{3}$ and this primer ${ }^{32} \mathrm{P}$ end-labeled was added as a loading control (l.c.). The incorporation of nontelomeric nucleotides from the downstream-flanking region of the template, readthrough, is denoted on the gel (red triangles). 
TRs (Chen et al. 2000; Lai et al. 2002; Dandjinou et al. 2004). Nonetheless, one echinoderm TR from the spiny brittle star (Ophiothrix spiculata) appears to lack a P1.1 stem-loop and structurally better resembles the vertebrate template/pseudoknot domain (Supplemental Fig. S2A).

In vertebrate $\mathrm{TR}$, the template boundary is defined by the core-enclosing P1b helix that restricts the availability of residues to be used as templates (Chen and Greider 2003). In contrast, the template boundary in fungal TR is defined by the template-adjacent helix (Tzfati et al. 2000; Dandjinou et al. 2004; Leonardi et al. 2008; Webb and Zakian 2008). To discern whether the echinoderm template-adjacent P1.1 helix functions as a template boundary element similar to fungal TR, we reconstituted purple sea urchin telomerase in vitro with TR mutants bearing insertions and/or deletions intended to alter the structure or shift the position of the P1.1 helix (Fig. 2E, top). To monitor nucleotide incorporation bypassing the template boundary, we generated the sea urchin TR mutant C22U/U41G in which the mutated $41 \mathrm{G}$ residue can be used as the template in the presence of dCTP when nucleotide addition bypasses the template boundary. The mutated residue $22 \mathrm{U}$ was introduced to prevent unintended base-pairing between the native $\mathrm{C} 22$ residue and $41 \mathrm{G}$, which could potentially extend the P1.1 helix and limit the use of $41 \mathrm{G}$ as template. Using the $\mathrm{C} 22 \mathrm{U} / \mathrm{U} 41 \mathrm{G}$ mutant as the parental construct, we generated three mutants, linker-1, -2 , and -3 , with insertions or deletions in the regions flanking the P1.1 helix (Fig. 2E, top). These telomerase mutants were reconstituted in vitro and analyzed by the direct primer-extension assay to assess enzymatic activity and template boundary definition. Our results showed that the linker-1 mutant with the insertion of two uridine residues between the template and the P1.1 stem-loop used $41 \mathrm{G}$ as template for nucleotide incorporation in the presence of dCTP, bypassing the normal template boundary (Fig. 2E, bottom, lanes 5,6). In vertebrate $\mathrm{TR}$, the length of the linker between the template and stem P1b is critical for template boundary definition (Chen and Greider 2003). We thus tested the importance of the distance between the template and P1b in purple sea urchin TR for maintaining template boundary. We generated mutant linker-2 that had the same two-residue insertion as the linker-1 mutant and a two-residue deletion in the linker between the P1b and P1.1 helices (Fig. 2E, top). The combination of the insertion and deletion maintained the overall distance between the template and P1b (Fig. 2E, top). Interestingly, the linker-2 mutation failed to prevent nucleotide addition bypassing the template boundary (Fig. 2E, bottom, lanes 7,8). This suggests that the linker length between P1b and P1.1, critical for vertebrate TR template boundary definition, is not important for template boundary definition in purple sea urchin. Furthermore, the linker-3 mutant, with two residues inserted in the linker between P1b and P1.1, had no significant effect on template boundary (Fig. 2E, lanes 9,10). Therefore, the P1.1 stem-loop is crucial for defining the echinoderm TR template boundary.
We then examined whether the echinoderm TR P1b can function as the template boundary element when the P1.1 helix has been removed. To test this, we first confirmed that the sea urchin P1b helix was dispensable in the presence of the P1.1 helix by removing the entire P1b helix with mutant $\triangle \mathrm{P} 1 \mathrm{~b}$ (Fig. 2F, top). The loss of the P1b helix did not disrupt the template boundary; the addition of dCTP did not alter the banding pattern of telomerase products (Fig. 2F, bottom, lanes 5,6). To explore the possibility of converting the sea urchin TR to use a vertebrate template boundary element, we generated mutants $\Delta \mathrm{P} 1.1-1,-2,-3$, and -4 by removing the P1.1 helix and introducing serial single nucleotide deletions in the new linker between the template and P1b (Fig. 2F, top). Our results demonstrated that mutants $\Delta \mathrm{P} 1.1-1$ and -2 with longer linker lengths between the template and P1b permitted visible nucleotide addition bypassing the end of the template in the presence of dCTP (Fig. 2F, bottom, lanes 7-10). Interestingly, mutants $\Delta \mathrm{P} 1.1-3$ and -4 , with shorter linker lengths between the template and P1b, showed little to no nucleotide addition bypassing the template boundary in the presence of dCTP (Fig. 2F, bottom, lanes 11-14). Thus, in the absence of P1.1, the length of the linker between the template and P1b appeared critical for template boundary definition, similar to the vertebrate mechanism.

We further investigated whether the helical structure of P1.1 is important for template boundary definition. Mutants $\mathrm{m} 1$ and $\mathrm{m} 2$ harbored mutations in one of the two strands to disrupt base-pairings, while mutant $\mathrm{m} 3$ had compensatory mutations to restore base-pairings in the P1.1 helix (Fig. $2 \mathrm{G}$, top). The $\mathrm{m} 1$ and $\mathrm{m} 2$ mutant showed impaired template boundary definition, allowing incorporation of dCTP using $41 \mathrm{G}$ as the template (Fig. 2G, bottom, lanes 6-8). The m3 mutant prevented nucleotide addition bypassing the end of the template in the absence or presence of dCTP, restoring the template boundary (Fig. 2G, bottom, lanes 9,10). Together, these data indicated that the P1.1 stem-loop, and not the P1b helix, functions as the template boundary element in echinoderm TR. However, the loss of the P1.1 helix can be compensated for by the P1b helix with a proper linker length, functioning as an ancillary template boundary.

\section{The echinoderm CR4/5 structural element}

Sea urchin, brittle star, and feather star TRs share no apparent sequence or structural homology in the central region, which lies between the template/pseudoknot and H/ACA domains. Moreover, the primary sequences of the echinoderm central region could not be aligned with the conserved CR4/5 sequences of vertebrate TR. We therefore discerned the secondary structures of the echinoderm central domain individually for each of the three echinoderm classes (Supplemental Fig. $\mathrm{S} 3 \mathrm{~A}, \mathrm{C})$. For sea urchin TRs, the alignment of the central domain sequences revealed noticeable sequence conservation within the latter half of this region (Supplemental Fig. S3A). To construct a secondary structure model of the sea urchin 
TR central domain, the aligned sequences were analyzed for nucleotide covariation. Secondary structure prediction was assisted by the mFold program (Zuker 2003). A preliminary model predicted two separate long stem-loop branches connected at their bases by the conserved P4 helix (Fig. 3B). The 3'-proximal helix, termed P4.2, showed a significantly higher sequence conservation than the $5^{\prime}$-proximal P4.1 helix (Supplemental Fig. S3A). For the brittle star TR, the central domain was predicted to fold into a single helix (Fig. 3C; Supplemental Fig. S3C). The small number of brittle star TRs did not provide appreciable nucleotide covariation support. The feather star TR central domain was also predicted to form a single, while much shorter, helix that is similar to the brittle star central domain (Fig. 3D). The identification of additional TRs from brittle and feather star species would be necessary to lend further nucleotide covariation support to these predicted single helical structures.

To refine the secondary structure of echinoderm TR central domain, we performed selective 2'-hydroxyl acylation analyzed by primer extension (SHAPE) to probe for unpaired nucleotides in the RNA structure. Overall, there was consid-
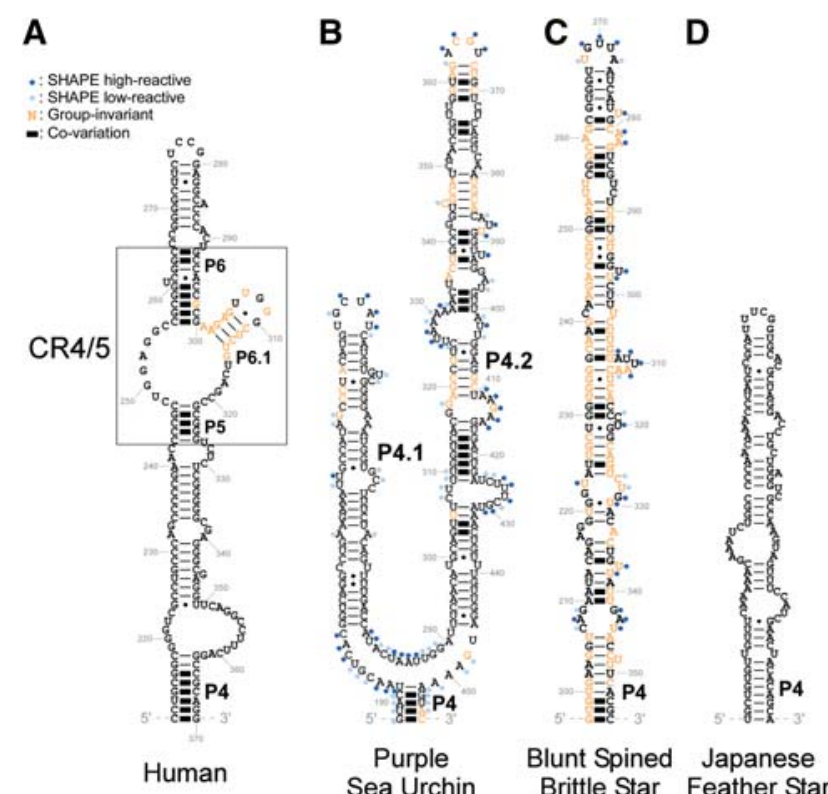

FIGURE 3. Structural divergence in the essential central domain between vertebrate, sea urchin, brittle star, and feather star TRs. Comparison of representative TR central domains from vertebrate, human $(A)$; sea urchin, purple sea urchin $(B)$; brittle star, blunt spined brittle star $(C)$; and feather star, Japanese feather star $(D)$. The minimal functional element for the stimulation of telomerase activity in vertebrates is CR4/5 (open box). Covariation (black bar) and group-invariant (orange) nucleotides for vertebrate, sea urchin, and brittle star TR central domains based on multiple sequence alignment of 42 vertebrate (Chen et al. 2000; Podlevsky et al. 2008; Xie et al. 2008), 10 sea urchin/sand dollar, 3 brittle star, and a feather star species (see Supplemental Fig. S3A,C). The purple sea urchin and blunt spined brittle star central domains were analyzed by SHAPE with flexibility (high, dark blue; low, light blue circles) and rigidity (no circle) of each residue denoted on the secondary structure (see Supplemental Fig. S3B,D). erable agreement between the SHAPE data and the secondary structure derived from the sequence alignment of 10 sea urchin TR sequences (Fig. 3B; Supplemental Fig. S3A,B). For the brittle star TR, the SHAPE analysis supported the central domain as a single helical structure (Fig. 3C; Supplemental Fig. S3C,D). Therefore, the secondary structure of the echinoderm central domain is unique among TRs, lacking the three-way junction configuration of the essential and ancestral CR4/5 structure found in vertebrate and fungal TRs (Chen et al. 2002; Qi et al. 2013).

Functional analysis of the echinoderm TR central domain was performed to determine the minimal region necessary and sufficient for reconstituting telomerase enzymatic activity (Fig. 4; Supplemental Fig. S4). We previously found that the purple sea urchin template/pseudoknot TR fragment and TERT protein are sufficient to reconstitute a basal level of telomerase activity, $\sim 40 \%$ of that generated with the inclusion of the P4.2 helix (Li et al. 2013). To further identify the regions in this $\mathrm{P} 4.2$ helical fragment dispensable for telomerase activity stimulation, we generated purple sea urchin TR P4.2 helix fragments, P4.2- $\Delta 1,-\Delta 2$, and $-\Delta 3$, by serially truncating from the apical loop and capping with the tetra-loop GAAA (Fig. 4A). Purple sea urchin telomerase was reconstituted with the purple sea urchin TERT, the template/pseudoknot domain, and these various $\mathrm{P} 4.2$ truncation fragments (Fig. 4B). Truncation mutation P4.2- $\Delta 1$, which removed nucleotides 342-388 from the helix, significantly reduced telomerase activity to $49 \%$ of the activity reconstituted with the entire P4.2 helix (Fig. 4B, lanes 1,4). The reduced activity of mutant P4.2- $\Delta 1$ was similar to the basal activity of the telomerase lacking the P4.2 helix (Fig. 4B, lanes 2,3). In contrast, truncation mutations $\mathrm{P} 4.2-\Delta 2$ and $-\Delta 3$ that removed the apical loop and helical regions from nucleotides 350 379 and 358-373, respectively, did not reduce telomerase activity (Fig. 4B, lanes 5,6). This suggests that the region from nucleotides 350-379 nt is not required for the function of the P4.2 helix.

We previously mapped the region of the $\mathrm{P} 4.2$ helix essential for activity stimulation to between nucleotides 332 and 400 (Li et al. 2013). By combining the previous minimal fragment with the P4.2- $\Delta 2$ truncation, we generated a $43-n t$ P4.2 fragment covering nucleotides 332-349 and nucleotides 380 400, termed P4.2- $\Delta 2$-mini (Fig. $4 \mathrm{C}$ ). As expected, this small RNA fragment was sufficient to stimulate telomerase activity to a similar level as the entire central P4.2 fragment (Fig. 4D, lane 4). Therefore, despite the considerable differences in the primary sequences and secondary structures, we concluded that the P4.2- $\Delta 2$-mini helix contains the structural element functionally equivalent to the vertebrate CR4/5 domain necessary for stimulating telomerase activity. In recognition of this functional homology, we termed the helical structure of P4.2- $\Delta 2$-mini the eCR4/5 domain for functionally equivalency to the vertebrate CR $4 / 5$ domain.

The eCR4/5 domain of purple sea urchin TR contains two bulged residues, C345 and U392, that are conserved across 


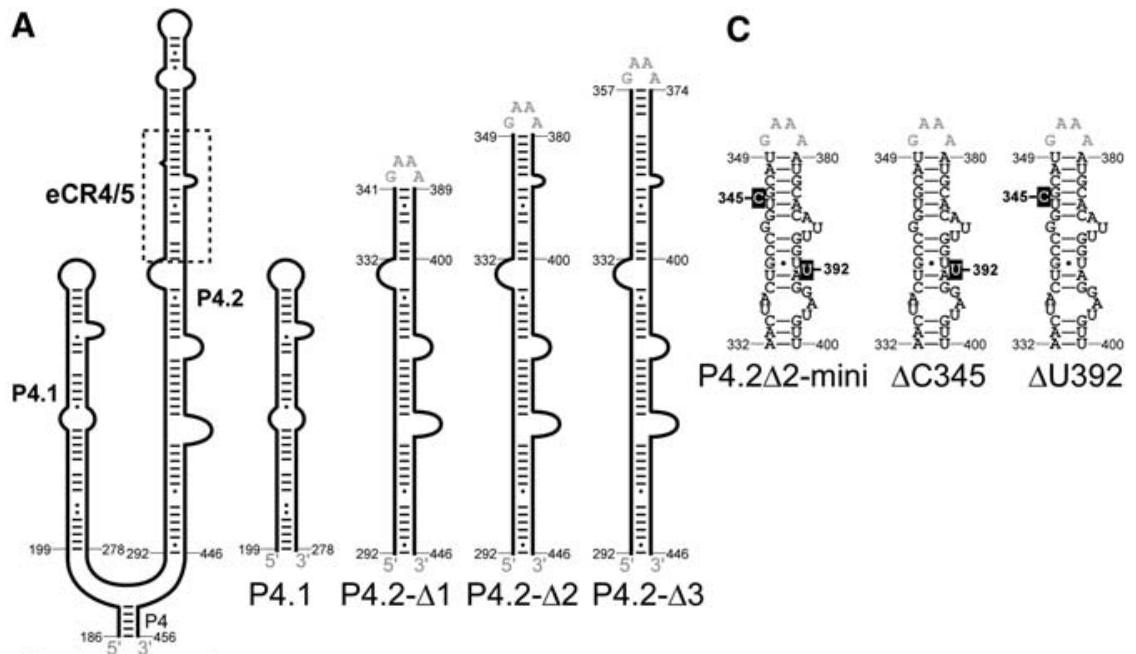

Central domain

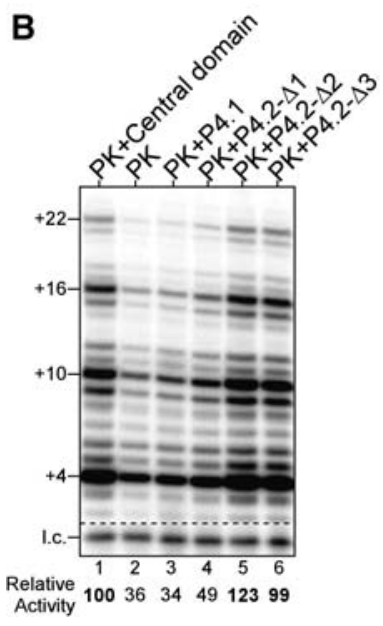

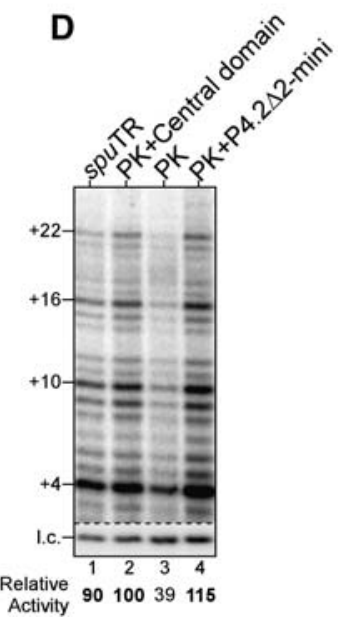

FIGURE 4. The echinoderm eCR $4 / 5$ is a functional homolog of the vertebrate CR4/5 domain. $(A, C)$ Schematic of the purple sea urchin TR central domain denoting nucleotide deletions (black shaded) and truncations to determine the minimal functional fragment sufficient for the stimulation of telomerase activity. Apical loop truncations were capped with a GNRA tetraloop (gray). The echinoderm eCR4/5 (dashed box), a functional homolog of vertebrate CR4/5, is denoted. $(B, D, E)$ Functional analysis of purple sea urchin TR mutations and truncation variants by the direct primer-extension assay. The purple sea urchin TR template/pseudoknot (PK) fragment (11$163 \mathrm{nt}$ ) and central domain variants were assembled in vitro with the sea urchin TERT protein. Sea urchin telomerase variants were assayed with the 18-mer DNA primer (TTAGGG) ${ }_{3}$ and this primer ${ }^{32} \mathrm{P}$ end-labeled was added as a loading control (l.c.). Relative activity of purple sea urchin TR variants compared against telomerase reconstituted with purple sea urchin TR PK and central domain RNA fragments is denoted below the gel.

sea urchin and sand dollar species (Fig. 3B; Supplemental Fig. S3A). Within the vertebrate CR4/5 domain, the P6 stem-loop contains a conserved single-nucleotide uridine bulge (Chen et al. 2000; Xie et al. 2008). The deletion of this uridine bulge drastically reduces binding of the medaka fish CR4/5 domain to its TERT protein (Bley et al. 2011). To investigate whether either single-nucleotide bulge in purple sea urchin eCR4/5 has a similar vital function for RNA-protein interaction, we generated single-residue deletion mutants of P4.2- $\Delta 2$ mini: $\Delta$ C345 and $\Delta$ U392 (Fig. 4C). The individual deletion of C345 or U392 abolished or severely reduced the stimula- tory function of eCR4/5 (Fig. 4E, lanes 2-4). Additionally, the telomerase stimulatory effect of echinoderm eCR $4 / 5$ is species-specific, as the vertebrate CR4/5 domain fragment from medaka fish TR failed to enhance activity of purple sea urchin telomerase (Fig. 4E, lane 5).

We further expanded our functional analysis of the echinoderm central domain to include the blunt spined brittle star (Supplemental Fig. S4). We generated various central domain fragments, $\mathrm{CD} \Delta 1,-\Delta 2,-\Delta 3,-\Delta 4$, and $-\Delta 5$, of the blunt spined brittle star TR by serially truncating from the base of the stem (Supplemental Fig. S4A). Brittle star telomerase was reconstituted with blunt spined brittle star TERT, the template/ pseudoknot domain and these various central domain fragments. Truncation mutations, $\mathrm{CD} \Delta 1,-\Delta 2,-\Delta 3$, and $-\Delta 4$, which removed up to $110 \mathrm{nt}$ from the helix retained similar telomerase activity as the entire central domain, demonstrating that the regions removed are dispensable (Supplemental Fig. S4B, lanes 1-5). In contrast, truncation mutation $\mathrm{CD} \Delta 5$ reduced activity to $67 \%$, similar to the basal level of activity generated with the template/pseudoknot domain alone, indicating the region removed from the CD- $\Delta 4$ fragment is crucial for activity (Supplemental Fig. S4B, lanes 6,7). We then generated additional truncation mutants, AL $\Delta 1,-\Delta 2,-\Delta 3,-\Delta 4$, and $-\Delta 5$, by serially truncating the brittle star TR central domain from the apical loop and capping the stem with the tetra-loop GAAA (Supplemental Fig. S4C). The activity assay of mutants AL $\Delta 1$ showed that the apical loop of brittle star TR central domain is dispensable for the stimulation of telomerase activity (Supplemental Fig. S4D, lanes 1,2). However, additional truncations from the apical loop with mutants $\operatorname{AL} \Delta 2,-\Delta 3,-\Delta 4$, and $-\Delta 5$ eliminated the stimulatory effect of the central domain fragment (Supplemental Fig. S4D, lanes 3-7). Thus, the brittle star eCR4/5 domain, like that of sea urchin, is an internalized helical region as opposed to the three-way-junction of helices found in the vertebrate CR4/5 domain. Interestingly, the brittle star reconstituted a basal level of telomerase activity at $\sim 70 \%$ of the full activity, while the sea urchin template/pseudoknot-TERT RNP generated only $40 \%$ of the full activity. Together, these results suggest that the sea urchin and brittle star eCR $4 / 5$ are functionally equivalent to the vertebrate 
CR4/5 despite the lack of sequence or structural conservation (Fig. 3).

\section{Echinoderm H/ACA domain}

The $3^{\prime}$ region of echinoderm TR harbors an H/ACA domain with the highly conserved sequence motifs and a secondary structure homologous to that of vertebrate TR (Fig. 5). Similar to the vertebrate H/ACA domain, the echinoderm H/ACA domain comprises the two universally conserved box $\mathrm{H}$ and ACA motifs separated by a stem-loop with two paired regions, P7 and P8. RACE analysis for select echinoderm species determined that the $3^{\prime}$-end of echinoderm TR lies three nucleotides downstream from the box ACA motif, identical to the vertebrate TR $3^{\prime}$-end (Chen et al. 2000; Xie et al. 2008). In sea urchin and brittle star TRs, the apical loop capping the $\mathrm{P} 8$ helix contains a conserved CAB box motif that is critical for vertebrate TR accumulation and Cajal body localization (Fig. 5B,C; Supplemental Fig. S5). However, a CAB box could not be found in the P8 loop of
A

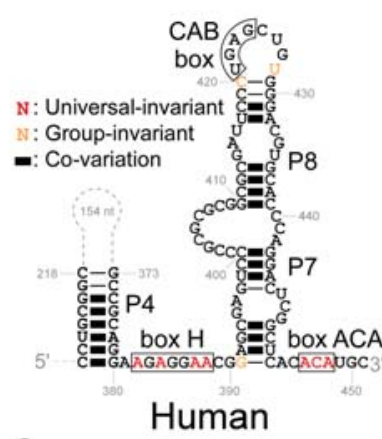

C

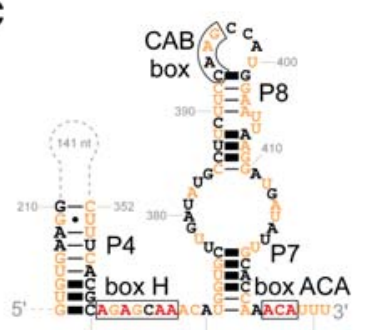

Blunt Spined Brittle Star
B

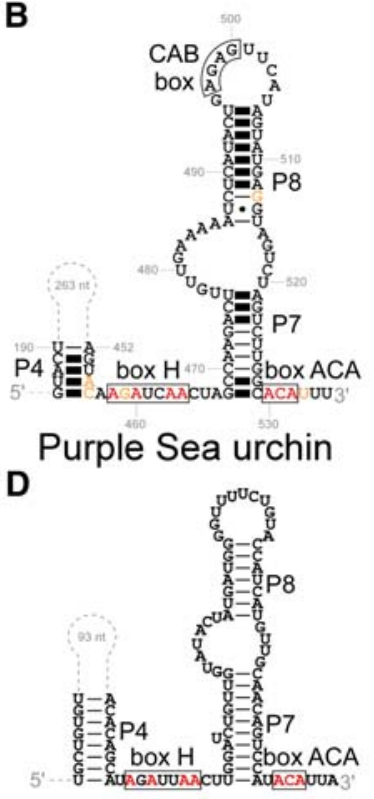

Japanese Feather Star
FIGURE 5. The vertebrate TR H/ACA domain is conserved throughout echinoderm TRs. Comparison of representative TR H/ACA domains from vertebrate, human $(A)$; sea urchin, purple sea urchin $(B)$; brittle star, blunt spined brittle star $(C)$; and feather star, Japanese feather $\operatorname{star}(D)$. The namesake box $\mathrm{H}$ and ACA moieties (open boxes) are present in echinoderm TRs with the full-length $3^{\prime}$-end identified. The CAB box (open box) is present in sea urchin and brittle star TRs. The CAB box is either lost or cryptic in teleost fish and feather star TRs. Covariation (black bar), universal-invariant between vertebrates and echinoderm (red), and group-invariant (orange) nucleotides for vertebrate, sea urchin, and brittle star TR H/ACA domains is based on multiple sequence alignment of 42 vertebrate (Chen et al. 2000; Podlevsky et al. 2008; Xie et al. 2008), 9 sea urchin/sand dollar, 3 brittle star, and a feather star species (see Supplemental Fig. S5). feather star TR (Fig. 5D). This apparent loss of the $\mathrm{CAB}$ box within feather star in echinoderms is not overly surprising as teleost fish TR also lacks a CAB box (Xie et al. 2008). The conservation of the H/ACA domain in echinoderm TRs suggested that the H/ACA small nucleolar/small Cajal body (sno-/sca-) RNA biogenesis pathway and 3'-end processing mechanism are similarly used by both vertebrate and echinoderm TRs.

\section{DISCUSSION}

The initial identification of purple sea urchin TR revealed structural domains homologous to the template/pseudoknot and H/ACA domains from vertebrate TRs (Li et al. 2013). Surprisingly, purple sea urchin TR seemingly lacks the essential ancestral CR4/5 structural domain that is evolutionarily conserved and functionally essential for vertebrate, filamentous fungal, and fission yeast telomerase activity (Qi et al. 2013). Phylogenetic comparative analysis of 14 echinoderm TRs, identified in this study, indicates that the CR4/5 threeway junction of helices has been functionally replaced with a simple internal helical region (Fig. 4). Interestingly, the overall architecture of echinoderm TRs appears chimeric, with elements common to vertebrate or fungal TRs, as well as echinoderm-specific structural features (Fig. 6).

The strategies that we used in this study to identify TR sequences from the echinoderm species rely on powerful RNAseq analysis of size-selected RNA samples and de novo transcriptome assembly of the sequencing reads. In addition, our simplified bioinformatics screening step using Fregrep2 program generated PWM facilitated identification of more divergent TR sequences than our previously used TR-PK-finder algorithm (Supplemental Fig. S1B). This spartan approach was successful for echinoderm TR identification and can be readily applied toward the identification of TRs from other unexplored groups of species that lack sequenced genomes and biochemically characterized telomerase.

Our functional characterization of the purple sea urchin TR template/pseudoknot domain revealed that the echinoderm TR template boundary is defined by the template-adjacent P1.1 stem-loop (Fig. 2). The P1.1 stem-loop resembles the template-adjacent helix in fungal TRs and Helix II in ciliate TRs (Podlevsky and Chen 2012). Fungal and ciliate template-adjacent helices function similarly by physically restricting the residues in the template-flanking region from being used as the template (Tzfati et al. 2000; Jansson et al. 2015). Instead of using a template-adjacent helix, vertebrate TR template boundary is defined by the more distant $\mathrm{P} 1 \mathrm{~b}$ helix and a single-stranded linker with a specific length to the template (Chen and Greider 2003). Due to its evolutionary proximity to vertebrates, echinoderm TR was expected to have a template boundary element reminiscent of the vertebrate mechanism (Fig. 1). It is rather surprising that echinoderm TR utilizes a template-adjacent helix to define its template boundary, a mechanism that is highly similar to fungal and ciliate 


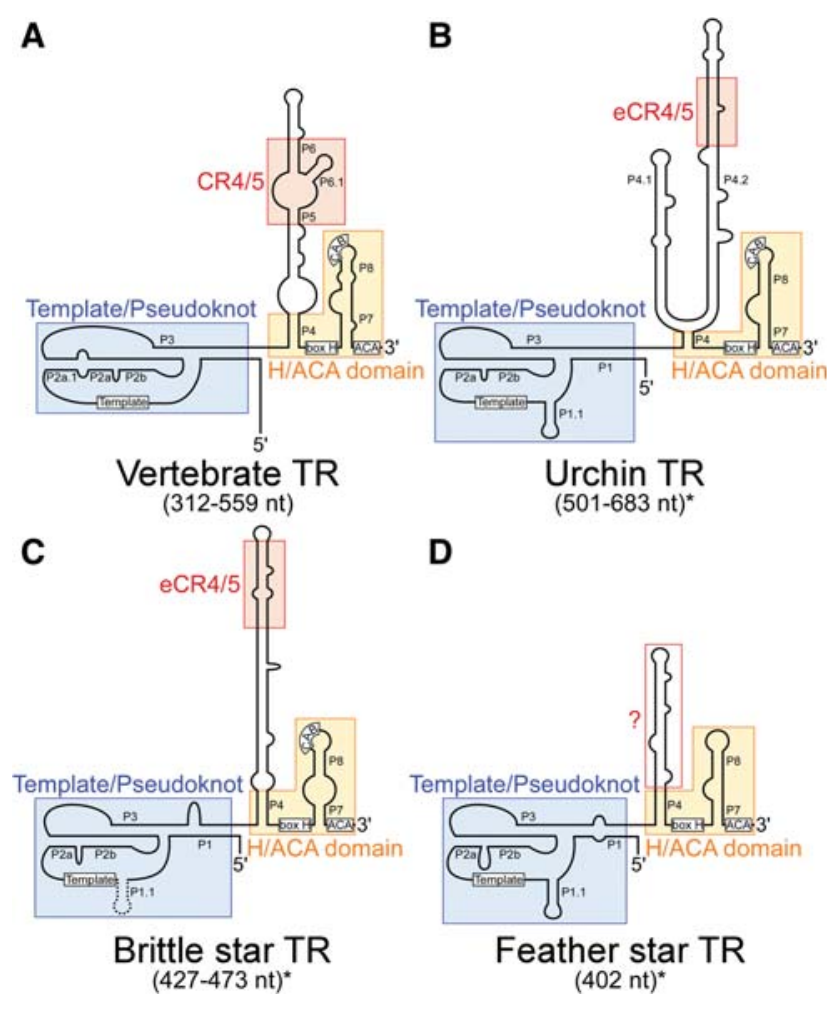

FIGURE 6. The central domain of vertebrate and echinoderm TRs is functionally equivalent yet structurally divergent. Schematic comparison of representative TRs for vertebrate, human $(A)$; sea urchin, purple sea urchin $(B)$; brittle star, blunt spined brittle star $(C)$; and feather star, Japanese feather star $(D)$. Vertebrate and echinoderm TR share structurally homologous template proximal pseudoknot (blue) and H/ACA (orange) domains. The sea urchin and brittle star eCR4/5 (red) are functionally homologous to vertebrate CR4/5 (red). A functionally homologous CR4/5 domain has yet to be determined (red box) for the feather star TR. Numbers below each schematic denote the known and putative $\left(^{*}\right)$ size ranges for TRs within each group.

TRs (Fig. 2). However, it remains unclear whether the echinoderm P1.1 stem-loop functions as a TERT protein binding site, similar to ciliate TR helix II, whereby TERT protein binding impedes the use of nucleotides as the template from outside the template boundary (Autexier and Greider 1995; Lai et al. 2002; Jansson et al. 2015). Moreover, as demonstrated in this study, the echinoderm P1.1 helix can be entirely removed and replaced with a specific linker length to the P1b helix which functions as the new template boundary element, using a mechanism identical to that of vertebrate TRs (Fig. $2 \mathrm{~F})$. Interestingly, the echinoderm P1.1 helix appears to have been lost within spiny brittle star TR, yet present within other brittle star TRs (Supplemental Fig. S2A). However, we suspect that the loss of P1.1 in spiny brittle star TR was an isolated event during evolution as TRs from other brittle stars and the more basal echinoderm species, feather star, preserve the template-adjacent P1.1 helix (Fig. 2).

The conserved three-way junction structure of the CR4/5 domain has been replaced with a simple helical structural eCR4/5 domain in echinoderm TR (Fig. 3). The echinoderm
eCR4/5 domain is functionally equivalent to the vertebrate and fungal CR4/5 domain, which is to stimulate telomerase activity (Fig. 4; Supplemental Fig. S4). The transition from the CR4/5 to the eCR4/5 domain along the echinoderm lineage was likely prompted by the gain-of-function of the echinoderm template/pseudoknot domain. Significant telomerase activity can be reconstituted from the echinoderm TERT and TR template/pseudoknot domain alone (Fig. 4B; Supplemental Fig. S4), a sharp contrast to vertebrate and filamentous fungal template/pseudoknot-TERT RNP complexes that rely absolutely upon CR4/5 binding for detectable telomerase activity (Chen et al. 2002; Qi et al. 2013). Due to the ancestry of the CR4/5 structural domain, it would appear that this critical and evolutionarily conserved structural element has diversified within the echinoderm phylum of species. The apparent loss of functional dependency on the CR4/5 is not exclusive to echinoderm TR. The budding yeast $\mathrm{TR}$, while having preserved the three-way junction of helices, lacks the highly conserved P6.1 stem-loop (Brown et al. 2007). Furthermore, a miniature version of the budding yeast TR that contains the template/pseudoknot domain, and lacks the three-way junction, is sufficient to confer a detectable telomerase activity and maintain telomere length (Zappulla et al. 2005). This suggests that the loss of function of the CR4/5 domain has been compensated by the gain of function of the yeast template/pseudoknot domain.

Throughout the echinoderm lineage, TR contains a $3^{\prime}$ H/ACA domain that has a highly conserved secondary structure and motifs homologous to the vertebrate H/ACA domain (Fig. 5). This strongly supports a similar TR sno-/ scaRNA biogenesis pathway and $3^{\prime}$-end processing mechanism between vertebrate and echinoderm TRs (Jády et al. 2004; Egan and Collins 2010). Additionally, the presence of a CAB box in the apical loop of the P8 helix in the echinoderm H/ACA domain indicates binding by a homolog of the vertebrate TCAB1 protein for Cajal body localization (Venteicher et al. 2009). Unexpectedly, the feather star H/ ACA domain lacks a CAB box in the P8 apical loop, which is similar to teleost fish TR as a vertebrate outlier (Xie et al. 2008). The absence of an apparent $C A B$ box would indicate either cryptic binding by a TCAB1 homolog, an alternative means of Cajal body localization, or an alternative biogenesis pathway.

The structural divergence of the eCR4/5 domain within various echinoderm TRs and the gain-of-function of the template/pseudoknot domain demonstrate functional coevolution of these two separate TR structural domains. Echinoderm template/pseudoknot-TERT RNP confers significant telomerase activity, reducing telomerase dependence on the ancestral CR4/5 domain. This would have permitted the rapid evolution and divergence in RNA structure by either gradual accumulation of mutations or a more drastic event that devastated and dismantled CR4/5 physically and functionally. Echinoderm TR has a template-adjacent P1.1 stemloop that is reminiscent of, and functionally homologous 
to, fungal and ciliate telomerases. Thus echinoderm TR possesses chimeric structural features - an amalgam of vertebrate and fungal functional elements, which expands our understanding of telomerase divergence and of RNA-protein coevolution.

\section{MATERIALS AND METHODS}

\section{Isolation of total RNA}

Gonadal tissue was dissected from live D. excentricus, O. panamense, and O. echinata (Marine Research and Educational Product and Live Aquaria). Total RNA was isolated from gonads using TRI-Reagent (Molecular Research Center, Inc.) following the manufacturer's instructions appended with an acid phenol extraction step prior to chloroform extraction and ethanol precipitation. RNA quality was determined by electrophoresis on a $1 \%$ agarose/formaldehyde denaturing gel.

\section{RNA preparation and RNA-seq}

Ten micrograms of total RNA for D. excentricus and O. panamense was resolved by electrophoresis on a $4 \%$ polyacrylamide/ $8 \mathrm{M}$ urea denaturing gel. The gel section, containing RNA species from 300-750 nt in length, was excised and RNA was eluted from the gel slice followed by ethanol precipitation. Size-selected RNA was used for cDNA library construction with the ScriptSeq v2 RNASeq Library Preparation Kit (Epicentre) following the manufacturer's instructions. The cDNA libraries were constructed with ScriptSeq Index PCR Primers (Epicentre) and indexed cDNA libraries were pooled for a single multiplexed single-end 50-bp sequencing run on a HiSeq 2000 (Illumina).

\section{Degenerate PCR}

Gonadal tissue was dissected from live A. punctulata, L. variegatus, and M. globulus (Live Aquaria). Partial TR genes were amplified from genomic DNA extracted from gonadal tissues by PCR using degenerate DNA primers (Supplemental Table 1). A $12.5 \mu \mathrm{L}$ PCR reaction was performed in $1 \times$ Ex Taq buffer (Takara) with $1 \mu \mathrm{M}$ forward primer, $1 \mu \mathrm{M}$ reverse primer, $100 \mu \mathrm{M}$ of each dNTP, $100 \mathrm{ng}$ of genomic DNA, and $0.3 \mathrm{U}$ ExTaq Hot Start DNA polymerase (Clontech). Forward and reverse primers were designed to target conserved sequences in the pseudoknot and H/ACA domains, respectively. The full-length genomic sequence of each TR gene were determined by ligation-mediated PCR using the Universal Genome Walker Kit (ClonTech) followed by sequencing as described previously (Chen et al. 2000).

\section{Sequence alignment analysis}

The multiple sequence alignment of vertebrate and echinoderm TRs was performed initially using the program BioEdit and the ClustalW algorithm. The alignments were further refined manually using the highly conserved regions and known motifs as anchor points. Closely related species were first aligned and the alignment expanded to include sequences from more divergent species.

\section{Bioinformatics analysis of next-generation sequencing data}

The next-generation sequencing data obtained from the pooled cDNA library samples were de-multiplexed and de novo assembled using the Trinity assembly program (Haas et al. 2013) with default parameters on the National Science Foundation Data Intensive Academic Grid shared computational cloud. The assembled transcripts were searched in the sense-strand direction using the Fragrep2 program (Mosig et al. 2006) with a PWM sequence pattern generated from the multiple sequence alignment of six vertebrate and four sea urchin TRs (Supplemental Fig. S1). This PWM pattern was relaxed for greater range in the spans between conserved sequences, permitting a more degenerate search. Transcriptome and genome data from NCBI SRA (http://www.ncbi.nlm.nih.gov/sra) were de novo assembled using the Trinity assembly program and searched with the Fragrep2 program.

\section{Determination of RNA $5^{\prime}$ - and $3^{\prime}$-ends}

The $5^{\prime}$ - and $3^{\prime}$-ends of D. excentricus, O. panamense, and O. echinata TRs were determined by Rapid Amplification of cDNA Ends (RACE) using the FirstChoice RLM-RACE kit (Ambion). For all other echinoderm TRs identified in this study, the $3^{\prime}$-end was predicted as $3 \mathrm{nt}$ downstream from the box ACA motif as previously described (Chen et al. 2000).

\section{SHAPE analysis}

The central domain of O. echinata and S. purpuratus TR were PCR amplified with primers appended with SHAPE-specific adapter sequences, as previously described (Wilkinson et al. 2006). These PCR products were used as templates for in vitro transcription. The adapter appended RNA was gel purified and ethanol precipitated. Two picomoles of purified RNA fragments was denatured in $0.5 \times \mathrm{TE}$ buffer $(\mathrm{pH} 8.0)$ at $95^{\circ} \mathrm{C}$ for $2 \mathrm{~min}$ and immediately placed on ice for $2 \mathrm{~min}$. The RNA was supplemented with a final concentration $1 \times$ RNA folding mix (100 mM HEPES at $\mathrm{pH} 8.0,6 \mathrm{mM}$ $\mathrm{MgCl}_{2}$, and $100 \mathrm{mM} \mathrm{NaCl}$ ), incubated at $30^{\circ} \mathrm{C}$ for $20 \mathrm{~min}$, and divided into half. The RNA was treated with either $6.5 \mathrm{mM} \mathrm{N}$-methylisatoic anhydride (NMIA) (Sigma) in anhydrous DMSO or DMSO only, incubated at $30^{\circ} \mathrm{C}$ for $1 \mathrm{~h}$ and $25 \mathrm{~min}$ (five NMIA hydrolysis half-lives), and ethanol precipitated. One picomole of ${ }^{32} \mathrm{P}$ endlabeled primer was added to the RNA samples in $0.5 \times \mathrm{TE}$ buffer $(\mathrm{pH} 8.0)$, incubated at $65^{\circ} \mathrm{C}$ for $5 \mathrm{~min}$ and $35^{\circ} \mathrm{C}$ for $5 \mathrm{~min}$, and then placed on ice. The mixture was supplemented with $1 \times$ SuperScript III First-strand buffer ( $50 \mathrm{mM}$ Tris- $\mathrm{HCl}$ at $\mathrm{pH} 8.3$, $75 \mathrm{mM} \mathrm{KCl}$, and $3 \mathrm{mM} \mathrm{MgCl}_{2}$ ), $5 \mathrm{mM}$ DTT, $0.5 \mathrm{mM}$ each dNTP, and $0.75 \mathrm{mM}$ ddGTP or ddATP for the untreated RNA, followed by incubation at $52^{\circ} \mathrm{C}$ for $1 \mathrm{~min}$, addition of $100 \mathrm{U}$ SuperScript III RT (Life Technologies), and incubation at $52^{\circ} \mathrm{C}$ for $10 \mathrm{~min}$. Alkaline hydrolysis was performed with a final concentration of $200 \mathrm{mM}$ sodium hydroxide and incubation at $95^{\circ} \mathrm{C}$ for $5 \mathrm{~min}$ and stopped by the addition of Acid Stop solution ( $77 \mathrm{mM}$ unbuffered Tris- $\mathrm{HCl}, 32 \%$ formamide and $8 \mathrm{mM}$ EDTA) incubated at $95^{\circ} \mathrm{C}$ for $5 \mathrm{~min}$. The DNA products were resolved on a $6.8 \%$ polyacrylamide/8 $\mathrm{M}$ urea denaturing gel. The gel was dried, exposed to a phosphorstorage screen, and imaged on a phosphorimager FXPro (Bio-Rad). NMIA reactivity was normalized by subtracting 
the lowest intensity value from all positions, followed by subtracting the intensity values of the DMSO control from the corresponding NMIA reaction.

\section{Brittle star TERT gene synthesis}

The brittle star (O. echinata) TERT gene was identified using the Basic Local Alignment Search Tool (BLAST) with the purple sea urchin TERT protein sequence as query against the O. echinata transcriptome contigs. The DNAWorks program was used to design 96 oligonucleotides to span the open reading frame of the brittle star TERT gene (Hoover and Lubkowski 2002). The synthetic gene was constructed by "oligo shuffling" as previously described with minor modifications (Stemmer et al. 1995). Oligonucleotides were pooled into four groups of $24(4 \mu \mathrm{M}$ each) and $1 \mu \mathrm{L}$ used in a $25 \mu \mathrm{L}$ PCR reaction with $1 \times$ Q5 Reaction buffer $(25 \mathrm{mM}$ TAPS$\mathrm{HCl}$ at $\mathrm{pH} 9.3,50 \mathrm{mM} \mathrm{KCl}, 2 \mathrm{mM} \mathrm{MgCl}_{2}$, and $1 \mathrm{mM} \beta$-mercaptoethanol), $0.2 \mathrm{mM}$ each dNTP, and 0.5 U of Q5 DNA Polymerase (NEB). One microliter of the previous PCR reaction was then used in a second $25 \mu \mathrm{L}$ PCR reaction with $0.5 \mu \mathrm{M}$ outermost oligonucleotides as primers. These PCR products were cloned into the pCITE4a vector with an N-terminal Flag epitope tag generating pN-Flag-oecTERT.

\section{Telomerase in vitro reconstitution}

The recombinant sea urchin and brittle star TERT proteins were synthesized from pN-Flag-spuTERT and pN-Flag-oecTERT, respectively, in a $5 \mu \mathrm{L}$ reaction at $30^{\circ} \mathrm{C}$ for 60 min using the TnT Quickcoupled transcription/translation kit (Promega), following the manufacturer's instructions. Various purple sea urchin and brittle star TR fragments were in vitro transcribed, gel purified, and added at a final concentration of $1 \mu \mathrm{M}$ to assemble with the TERT protein in $\mathrm{RRL}$ at $30^{\circ} \mathrm{C}$ for $30 \mathrm{~min}$.

\section{Telomerase activity assay}

Telomerase activity was assayed by the direct primer-extension assay (Li et al. 2013). A $10 \mu \mathrm{L}$ reaction was performed with $2 \mu \mathrm{L}$ in vitro reconstituted telomerase in $1 \times$ telomerase reaction buffer $(50 \mathrm{mM}$ Tris- $\mathrm{HCl}$ at $\mathrm{pH} 8.3,2 \mathrm{mM}$ DTT, $0.5 \mathrm{mM} \mathrm{MgCl}_{2}$, and $1 \mathrm{mM}$ spermidine), $100 \mu \mathrm{M}$ dTTP, $100 \mu \mathrm{M}$ dATP, $2 \mu \mathrm{M}$ dGTP, $0.33 \mu \mathrm{M}\left[\alpha^{32} \mathrm{P}\right]$ dGTP $(3000 \mathrm{Ci} / \mathrm{mmol}, 10 \mathrm{mCi} / \mathrm{mL}$, Perkin-Elmer) and $1 \mu \mathrm{M}$ (TTAGGG) ${ }_{3}$ DNA primer. The reaction was incubated at $30^{\circ} \mathrm{C}$ for $1 \mathrm{~h}$ and terminated by phenol/chloroform extraction followed by ethanol precipitation. The telomerase extended products were resolved on a $10 \%$ polyacrylamide/ $8 \mathrm{M}$ urea denaturing gel, and the dried gel was exposed to a phosphorstorage screen and analyzed with a Molecular Imager FX-Pro (Bio-Rad).

\section{DATA DEPOSITION}

The complete sequences of echinoderm TRs determined in this study have been deposited in the GenBank under accession numbers KT279799-KT279804. The echinoderm TR sequences identified from assembly of transcriptome data have been deposited in the Telomerase Database (Podlevsky et al. 2008).

\section{SUPPLEMENTAL MATERIAL}

Supplemental material is available for this article.

\section{ACKNOWLEDGMENTS}

This work was supported by National Institutes of Health grant GM094450 (to J.J.-L.C). The assembly of next-generation sequencing data was performed using the Data Intensive Academic Grid shared computational cloud funded by National Science Foundation MRI-R2 project DBI-0959894.

Received July 13, 2015; accepted October 23, 2015.

\section{REFERENCES}

Autexier C, Greider CW. 1995. Boundary elements of the Tetrahymena telomerase RNA template and alignment domains. Genes Dev 9: 2227-2239.

Beilstein MA, Brinegar AE, Shippen DE. 2012. Evolution of the Arabidopsis telomerase RNA. Front Genet 3: 188.

Bley CJ, Qi X, Rand DP, Borges CR, Nelson RW, Chen JJ-L. 2011. RNAprotein binding interface in the telomerase ribonucleoprotein. Proc Natl Acad Sci 108: 20333-20338.

Brown Y, Abraham M, Pearl S, Kabaha MM, Elboher E, Tzfati Y. 2007. A critical three-way junction is conserved in budding yeast and vertebrate telomerase RNAs. Nucleic Acids Res 35: 6280-6289.

Cameron RA, Kudtarkar P, Gordon SM, Worley KC, Gibbs RA. 2015. Do echinoderm genomes measure up? Mar Genomics 22: 1-9.

Chen J-L, Greider CW. 2003. Template boundary definition in mammalian telomerase. Gene Dev 17: 2747-2752.

Chen J-L, Greider CW. 2004. Telomerase RNA structure and function: implications for dyskeratosis congenita. Trends Biochem Sci 29: 183-192.

Chen J-L, Blasco MA, Greider CW. 2000. Secondary structure of vertebrate telomerase RNA. Cell 100: 503-514.

Chen J-L, Opperman KK, Greider CW. 2002. A critical stem-loop structure in the CR4-CR5 domain of mammalian telomerase RNA. Nucleic Acids Res 30: 592-597.

Cifuentes-Rojas C, Kannan K, Tseng L, Shippen DE. 2011. Two RNA subunits and POT1a are components of Arabidopsis telomerase. Proc Natl Acad Sci 108: 73-78.

Dandjinou AT, Lévesque N, Larose S, Lucier JF, Abou Elela S, Wellinger RJ. 2004. A phylogenetically based secondary structure for the yeast telomerase RNA. Curr Biol 14: 1148-1158.

Egan ED, Collins K. 2010. Specificity and stoichiometry of subunit interactions in the human telomerase holoenzyme assembled in vivo. Mol Cell Biol 30: 2775-2786.

Egan ED, Collins K. 2012. An enhanced H/ACA RNP assembly mechanism for human telomerase RNA. Mol Cell Biol 32: 2428-2439.

Gillard GB, Garama DJ, Brown CM. 2014. The transcriptome of the NZ endemic sea urchin Kina (Evechinus chloroticus). BMC Genomics 15: 45.

Greider CW, Blackburn EH. 1989. A telomeric sequence in the RNA of Tetrahymena telomerase required for telomere repeat synthesis. Nature 337: 331-337.

Gunisova S, Elboher E, Nosek J, Gorkovoy V, Brown Y, Lucier JF, Laterreur N, Wellinger RJ, Tzfati Y, Tomaska L. 2009. Identification and comparative analysis of telomerase RNAs from Candida species reveal conservation of functional elements. RNA 15: 546-559.

Gupta SK, Kolet L, Doniger T, Biswas VK, Unger R, Tzfati Y, Michaeli S. 2013. The Trypanosoma brucei Telomerase RNA (TER) homologue binds core proteins of the C/D snoRNA family. FEBS Lett 587: 1399-1404. 
Haas BJ, Papanicolaou A, Yassour M, Grabherr M, Blood PD, Bowden J, Couger MB, Eccles D, Li B, Lieber M, et al. 2013. De novo transcript sequence reconstruction from RNA-seq using the Trinity platform for reference generation and analysis. Nat Protoc 8: 1494-1512.

Hoover DM, Lubkowski J. 2002. DNAWorks: an automated method for designing oligonucleotides for PCR-based gene synthesis. Nucleic Acids Res 30: e43.

Hughes TR, Evans SK, Weilbaecher RG, Lundblad V. 2000. The Est3 protein is a subunit of yeast telomerase. Curr Biol 10: 809-812.

Jády BE, Bertrand E, Kiss T. 2004. Human telomerase RNA and box H/ ACA scaRNAs share a common Cajal body-specific localization signal. J Cell Biol 164: 647-652.

Jansson LI, Akiyama BM, Ooms A, Lu C, Rubin SM, Stone MD. 2015. Structural basis of template-boundary definition in Tetrahymena telomerase. Nat Struct Mol Biol doi: 10.1038/nsmb.3101.

Lai C, Miller MC, Collins K. 2002. Template boundary definition in Tetrahymena telomerase. Gene Dev 16: 415-420.

Lattmann S, Stadler MB, Vaughn JP, Akman SA, Nagamine Y. 2011. The DEAH-box RNA helicase RHAU binds an intramolecular RNA Gquadruplex in TERC and associates with telomerase holoenzyme. Nucleic Acids Res 39: 9390-9404.

Leonardi J, Box JA, Bunch JT, Baumann P. 2008. TER1, the RNA subunit of fission yeast telomerase. Nat Struct Mol Biol 15: 26-33.

Li Y, Podlevsky JD, Marz M, Qi X, Hoffmann S, Stadler PF, Chen JJ-L. 2013. Identification of purple sea urchin telomerase RNA using a next-generation sequencing based approach. RNA 19: 852-860.

Mitchell JR, Cheng J, Collins K. 1999. A box H/ACA small nucleolar RNA-like domain at the human telomerase RNA 3' end. Mol Cell Biol 19: 567-576.

Mosig A, Sameith K, Stadler PF. 2006. Fragrep: An efficient search tool for fragmented patterns in genomic sequences. Genomics Proteomics Bioinformatics 4: 56-60.

Perseke M, Bernhard D, Fritzsch G, Brümmer F, Stadler PF, Schlegel M. 2010. Mitochondrial genome evolution in Ophiuroidea, Echinoidea, and Holothuroidea: insights in phylogenetic relationships of Echinodermata. Mol Phylogenet Evol 56: 201-211.

Podlevsky JD, Chen JJ-L. 2012. It all comes together at the ends: telomerase structure, function, and biogenesis. Mutat Res 730: 3-11.

Podlevsky JD, Bley CJ, Omana RV, Qi X, Chen JJ-L. 2008. The telomerase database. Nucleic Acids Res 36: D339-D343.

Qi X, Li Y, Honda S, Hoffmann S, Marz M, Mosig A, Podlevsky JD, Stadler PF, Selker EU, Chen JJ-L. 2013. The common ancestral core of vertebrate and fungal telomerase RNAs. Nucleic Acids Res 41: $450-462$.
Schmidt JC, Cech TR. 2015. Human telomerase: biogenesis, trafficking, recruitment, and activation. Genes Dev 29: 1095-1105.

Seto AG, Zaug AJ, Sobel SG, Wolin SL, Cech TR. 1999. Saccharomyces cerevisiae telomerase is an Sm small nuclear ribonucleoprotein particle. Nature 401: 177-180.

Sexton AN, Collins KL. 2011. The 5' guanosine tracts of human telomerase RNA are recognized by the G-quadruplex binding domain of the RNA helicase DHX36 and function to increase RNA accumulation. Mol Cell Biol 31: 736-743.

Singh M, Wang Z, Koo BK, Patel A, Cascio D, Collins K, Feigon J. 2012. Structural basis for telomerase RNA recognition and RNP assembly by the holoenzyme La family protein p65. Mol Cell 47: 16-26.

Sodergren E, Weinstock GM, Davidson EH, Cameron RA, Gibbs RA, Angerer RC, Angerer LM, Arnone MI, Burgess DR, Burke RD, et al. 2006. The genome of the sea urchin Strongylocentrotus purpuratus. Science 314: 941-952.

Stemmer WP, Crameri A, Ha KD, Brennan TM, Heyneker HL. 1995. Single-step assembly of a gene and entire plasmid from large numbers of oligodeoxyribonucleotides. Gene 164: 49-53.

Tang W, Kannan R, Blanchette M, Baumann P. 2012. Telomerase RNA biogenesis involves sequential binding by $\mathrm{Sm}$ and Lsm complexes. Nature 484: 260-264.

Tzfati Y, Fulton TB, Roy J, Blackburn EH. 2000. Template boundary in a yeast telomerase specified by RNA structure. Science 288: 863-867.

Venteicher AS, Abreu EB, Meng Z, McCann KE, Terns RM, Veenstra TD, Terns MP, Artandi SE. 2009. A human telomerase holoenzyme protein required for Cajal body localization and telomere synthesis. Science 323: 644-648.

Webb CJ, Zakian VA. 2008. Identification and characterization of the Schizosaccharomyces pombe TER1 telomerase RNA. Nat Struct Mol Biol 15: 34-42.

Wilkinson KA, Merino EJ, Weeks KM. 2006. Selective 2' -hydroxyl acylation analyzed by primer extension (SHAPE): quantitative RNA structure analysis at single nucleotide resolution. Nat Protoc 1: $1610-1616$.

Xie M, Mosig A, Qi X, Li Y, Stadler PF, Chen JJ-L. 2008. Structure and function of the smallest vertebrate telomerase RNA from teleost fish. J Biol Chem 283: 2049-2059.

Zakian VA. 2009. The ends have arrived. Cell 139: 1038-1040.

Zappulla DC, Goodrich K, Cech TR. 2005. A miniature yeast telomerase RNA functions in vivo and reconstitutes activity in vitro. Nat Struct Mol Biol 12: 1072-1077.

Zuker M. 2003. Mfold web server for nucleic acid folding and hybridization prediction. Nucleic Acids Res 31: 3406-3415. 

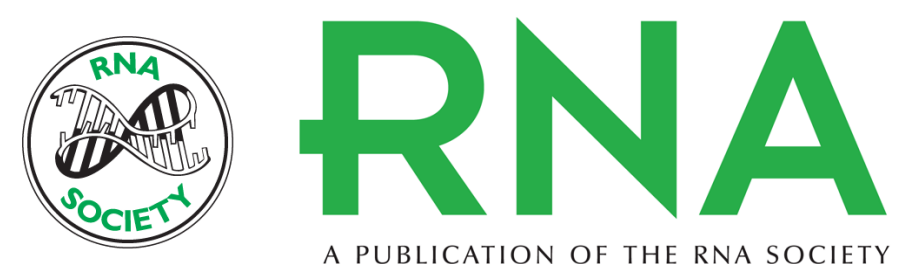

A PUBLICATION OF THE RNA SOCIETY

\title{
Structure and function of echinoderm telomerase RNA
}

\author{
Joshua D. Podlevsky, Yang Li and Julian J.-L. Chen
}

RNA 2016 22: 204-215 originally published online November 23, 2015

Access the most recent version at doi:10.1261/rna.053280.115

Supplemental Material

References

Creative Commons License

Email Alerting Service
http://rnajournal.cshlp.org/content/suppl/2015/11/20/rna.053280.115.DC1

This article cites 47 articles, 17 of which can be accessed free at: http://rnajournal.cshlp.org/content/22/2/204.full.html\#ref-list-1

This article is distributed exclusively by the RNA Society for the first 12 months after the full-issue publication date (see http://rnajournal.cshlp.org/site/misc/terms.xhtml). After 12 months, it is available under a Creative Commons License (Attribution-NonCommercial 4.0 International), as described at http://creativecommons.org/licenses/by-nc/4.0/.

Receive free email alerts when new articles cite this article - sign up in the box at the top right corner of the article or click here.

To subscribe to RNA go to:

http://rnajournal.cshlp.org/subscriptions 